\title{
EFFECT OF SPEED OF LOADING ON COMPRESSIVE STRENGTH AND FLEXURAL STRENGTH OF DENTAL RESIN-COMPOSITES
}

\author{
Samy M El-Safty*
}

\begin{abstract}
Objective: To investigate the effect of speed of loading on compressive strength and flexural strength for a range of dental resin-composites of varied composition.

Materials and Methods: For compressive strength testing, fifteen cylindrical specimens ( $4 \mathrm{~mm}$ diameter $\times 6 \mathrm{~mm}$ length) were prepared from each material using stainless steel split molds. Each specimen was irradiated from top and bottom in the mold and from radial direction after removing from the mold (40 s each) using a visible light curing unit (Optilux 501, Kerr, Orange Co., USA) with irradiance of $650 \mathrm{~mW} / \mathrm{cm}^{2}$. For flexural strength testing, fifteen bar-shaped specimens (25 mm length $\times 2 \mathrm{~mm}$ width $\mathrm{x} 2 \mathrm{~mm}$ height) were prepared from each material using stainless steel split molds. Each specimen was irradiated in five overlapping sections (40 s each) on the upper and lower surfaces starting from the center of the specimen using the visible light curing unit described above. Specimens were stored in distilled water at $37^{\circ} \mathrm{C}$ in an incubator for $24 \mathrm{~h}$. Loading of specimens until fracture, for both compressive strength and flexural strength, was carried out in a universal testing machine (model 3365, Instron, High Wycombe, UK) at three different cross-head speeds: $1 \mathrm{~mm} / \mathrm{min}(n=5), 3 \mathrm{~mm} / \mathrm{min}(n=5)$ and $5 \mathrm{~mm} / \mathrm{min}(n=5)$. Data were analyzed using a One-way ANOVA and Bonferroni post-hoc test.
\end{abstract}

Results: Considering all cross-head speeds applied, mean data for compressive strength ranged from 349 to $434 \mathrm{MPa}$, and for flexural strength ranged from 84 to $182 \mathrm{MPa}$. Linear regression analysis revealed a strong positive correlation between the applied cross-head speeds and both the compressive strength and flexural strength values.

Conclusions: Changing the cross-head speed resulted in variation in strength values of the investigated resin-composites. The values of compressive strength and flexural strength depend principally on the extent of filler loading and the type of resin system.

KEYWORDS: Compressive Strength, Flexural Strength, Resin-composites, Cross-head Speed, Filler Loading, Resin System.

* Lecturer at Biomaterials Department, School of Dentistry, Tanta University, Tanta, Egypt. 


\section{INTRODUCTION}

The use of resin-composites as restorative filling materials in load-bearing areas is increasing. This means that these materials are subjected to masticatory forces of a considerable magnitude ${ }^{[1,2]}$. Clinical performance and laboratory evaluation are the main approaches to understand and prove the reliability of a dental material ${ }^{[3]}$.

Successful application of dental materials as load-bearing structural components of restored teeth requires adequate mechanical properties. Thus general mechanical characterization of such materials is essential. The most useful starting point is to examine their stress-strain properties ${ }^{[4]}$.

Measurement of mechanical properties such as strength and modulus of elasticity is important for characterizing - in part - a resin-composite material and helps to predict the clinical performance and durability of its restoration ${ }^{[5]}$. The filler particles - in terms of composition, shape, content, interparticle spacing, and surface treatment - determine, to a great extent, the mechanical properties of resincomposites ${ }^{[6]}$. In addition to the filler system, monomer system of the resin matrix also influences the mechanical properties of these materials ${ }^{[7]}$.

Moreover, mechanical properties of such materials are influenced by the surrounding environment. The degradation process initiated by the water and the presence of a constant load generated by the masticatory system on the surface of the resin-composite material can start and propagate interfacial debonding, matrix cracking, filler dissolution, filler particle dislodgment and superficial flaws ${ }^{[8,9]}$.

For a resin-based restoration to be successful, it must be capable of resisting both masticatory and parafunctional stresses and maintaining its integrity while transferring stresses to the tooth structure, particularly in case of expecting stresses of high magnitude. In addition, this material must function in a complex environment characterized by fluids of varying composition and $\mathrm{pH}$, varying temperature conditions and cyclic mechanical forces ${ }^{[10]}$. It was reported that the stresses falling on the dental restoration may be one or a combination of three basic types; compressive, tensile and shear stresses $^{[11]}$.

Strength has been considered an essential mechanical property of a dental restorative material ${ }^{[12]}$. Strength values of resin-based restorative materials are usually related to their composition $^{[13]}$, irradiation time and packing procedures ${ }^{[5}$, ${ }^{14]}$. Strength properties have been utilized to characterize and compare resin-composite materials ${ }^{[15]}$.

Because of majority of the masticatory forces falling on the dentition are of a compressive nature, compressive strength of a restorative dental material has a particularly important role in the mastication process ${ }^{[16]}$. Flexural strength is a measure of material resistance to withstand tensile forces. Materials with high flexural strength provide restorations with higher resistance to fracture of the margins or the bulk ${ }^{[17]}$.

In stress-bearing occlusal areas, materials with low strength values deform more under masticatory stresses and may undergo catastrophic failure. High strength is required to withstand deformation and cuspal fracture ${ }^{[18]}$. Consequently, knowledge of the strength properties of many resin-composite materials is important in understanding and expecting their clinical behavior ${ }^{[19]}$.

The primary objective of this study was to investigate the effect of speed of loading on the compressive strength and flexural strength of some resin-composite materials of different types (Conventional, Flowable and Bulk-fill). The null hypotheses were: (i) there will be no difference in strength values between resin-composites with different composition and (ii) varying the speed of loading (cross-head speed) will have no effect on the strength values of the investigated resincomposites. 


\section{MATERIALS AND METHODS}

Five resin-composites (three conventional, one flowable and one bulk-fill) were investigated in this study. Materials and manufacturers' details are listed in Table 1.

\section{Specimen Preparation and Measurement of Compressive Strength}

Fifteen cylindrical specimens $(4 \mathrm{~mm}$ diameter $\times 6 \mathrm{~mm}$ length) were prepared from each material using stainless steel split molds. Glass microscope slides, covered with transparent polystyrene matrix films, were positioned at the upper and lower surfaces of the specimen. Each specimen was cured from top and bottom in the mold (40 s each) using a visible light curing unit (Optilux 501, Kerr, Orange Co., USA) with irradiance of $650 \mathrm{~mW} / \mathrm{cm}^{2}$.

After removing the specimen from the mold, excess material was trimmed by hand-grinding with P800 grit Silicone Carbide (SiC) abrasive paper. Each specimen was further cured from the radial direction (40 s each) and stored in distilled water at $37^{\circ} \mathrm{C}$ in an incubator for $24 \mathrm{~h}$. Loading of specimens until fracture was carried out in a universal testing machine (model 3365, Instron, High Wycombe, UK) at three different cross-head speeds: $1 \mathrm{~mm} / \mathrm{min}$ $(n=5), 3 \mathrm{~mm} / \mathrm{min}(n=5)$, and $5 \mathrm{~mm} / \mathrm{min}(n=5)$.
The compressive strength $\left(\boldsymbol{\sigma}_{\mathbf{c}}-\mathrm{MPa}\right)$ was calculated by dividing the maximum force applied to fracture the specimen by the cross-sectional area according to the following equation ${ }^{[16,20]}$ :

$$
\sigma_{C}=\frac{4 F}{\pi D^{2}}
$$

Where $F(\mathrm{~N})$ is the load at fracture, $\mathrm{D}(\mathrm{mm})$ is the diameter of the specimen.

\section{Specimen Preparation and Measurement of Flexural Strength}

Fifteen bar-shaped specimens ( $15 \mathrm{~mm}$ length $\mathrm{x} 2$ $\mathrm{mm}$ width $\mathrm{x} 2 \mathrm{~mm}$ height) were prepared from each material using stainless steel split molds. The resincomposite material was packed (conventional) or injected (flowable) into the mold and pressed with a glass microscope slide, covered with a transparent polystyrene matrix film. Each specimen was cured in five overlapping sections (40 s each) on the upper and lower surfaces starting from the center of the specimen using the visible light curing unit described above. After curing, specimens were removed from the mold and abraded by hand with 800 grit $\mathrm{SiC}$ abrasive paper to remove the excess material and stored in distilled water at $37^{\circ} \mathrm{C}$ for $24 \mathrm{~h}$ before loading.

TABLE (1) Investigated resin-composites; product code, material composition and manufacturers' information.

\begin{tabular}{|c|c|c|c|c|c|}
\hline Product & Code & Type & Manufacturer & Resin System & Filler (wt \%) \\
\hline GrandioSo & GS & Conventional & $\begin{array}{c}\text { Voco, Cuxhaven, } \\
\text { Germany }\end{array}$ & $\begin{array}{c}\text { Bis-GMA, Bis-EMA, } \\
\text { TEGDMA }\end{array}$ & 89 \\
\hline $\begin{array}{c}\text { Filtek Supreme } \\
\text { XTE }\end{array}$ & FS & Conventional & $\begin{array}{c}\text { 3M ESPE, St. Paul, MN, } \\
\text { USA }\end{array}$ & $\begin{array}{c}\text { Bis-GMA, UDMA, TEGDMA, } \\
\text { PEGDMA, Bis-EMA }\end{array}$ & 79 \\
\hline Venus Diamond & VD & Conventional & $\begin{array}{c}\text { Heraeus Kulzer GmbH, } \\
\text { Hanau, Germany }\end{array}$ & TCD, di-HEA, UDMA & 81 \\
\hline Venus Flow & VF & Flowable & $\begin{array}{c}\text { Heraeus Kulzer, Hanau, } \\
\text { Germany }\end{array}$ & Bis-GMA, TEGDMA & 62 \\
\hline $\begin{array}{c}\text { SureFil SDR } \\
\text { Flow }\end{array}$ & SF & Bulk-fill & $\begin{array}{c}\text { Dentsply Caulk, } \\
\text { Delaware, USA }\end{array}$ & $\begin{array}{c}\text { EBPADMA, } \\
\text { TEGDMA }\end{array}$ & 68 \\
\hline
\end{tabular}


Loading of specimens until fracture was carried out in the same universal testing machine described above using a three-point bending method with a 20-mm span at three different cross-head speeds: 1 $\mathrm{mm} / \mathrm{min}(n=5), 3 \mathrm{~mm} / \mathrm{min}(n=5)$ and $5 \mathrm{~mm} / \mathrm{min}$ $(n=5)$. The load at fracture and specimen dimensions were used to calculate the flexural strength $\left(\sigma_{\mathbf{f}}-\mathrm{MPa}\right)$ according to the following equation ${ }^{[21,22]}$.

$$
\sigma_{f}=\frac{3 F L}{2 b h^{2}}
$$

Where $F(\mathrm{~N})$ is the load at fracture, $L(\mathrm{~mm})$ is the distance between the supports, $b(\mathrm{~mm})$ is the width, and $h(\mathrm{~mm})$ is the height of the specimen.

\section{Statistical analysis}

Data for compressive strength and flexural strength were analyzed using a one-way analysis of variance (ANOVA) with the significance level established at $(\mathrm{p} \leq 0.05)$. The Bonferroni post $h o c$ test was used to determine the differences in compressive strength and flexural strength between groups. Linear regression analysis was performed to investigate relationship between investigated strengths and the applied cross-head speeds and between strength values and the filler loading of the corresponding materials.

\section{RESULTS}

Mean values and standard deviations of the compressive strength and flexural strength for the investigated resin-composites are listed in Table 2 and presented in Figures 1 and 2 respectively.

Mean data for the compressive strength ranged from 349 to $427 \mathrm{MPa}$ at a cross-head speed of $1 \mathrm{~mm} /$ min, from 358 to $429 \mathrm{MPa}$ at a cross-head speed of $3 \mathrm{~mm} / \mathrm{min}$, and from 367 to $434 \mathrm{MPa}$ at a cross-head speed of $5 \mathrm{~mm} / \mathrm{min}$. For the flexural strength, data ranged from 84 to $175 \mathrm{MPa}$ at a cross-head speed of $1 \mathrm{~mm} / \mathrm{min}$, from 96 to $178 \mathrm{MPa}$ at a cross-head speed of $3 \mathrm{~mm} / \mathrm{min}$, and from 105 to $182 \mathrm{MPa}$ at a cross-head speed of $5 \mathrm{~mm} / \mathrm{min}$.
The highest compressive strength was shown by GS followed by FS and VD and and the lowest values were recorded for SF followed by VF. The case for the flexural strength was exactly the same as the compressive strength.

Statistical analysis revealed significant differences between the investigated resincomposites at the three cross-head speeds applied; at $1 \mathrm{~mm} / \mathrm{min},(\mathrm{p}=0.012)$, at $3 \mathrm{~mm} / \mathrm{min},(\mathrm{p}=0.009)$, and at $5 \mathrm{~mm} / \mathrm{min},(\mathrm{p}=0.006)$.

Bonferroni post-hoc test revealed significant differences between GS and both of VF and SF but not with FS and VD. Similarly, FS exhibited significant differences with both of VF and SF but not with GS and VD. On the other hand, VD did not show significant differences with any of the investigated materials. This applies for both compressive strength data as well as flexural strength data.

From the data recorded, with increasing the cross-head speed, all investigated resin-composites, systematically, exhibited greater mean values for both compressive strength and flexural strength as shown in Table 2 and presented in Figures 1 and 2.

Variation in cross-head speed had a greater influence on the results of materials with flowable consistency than those with conventional consistency. This means that increasing the crosshead speed produced greater values in the strength data (both in compressive strength and flexural strength). This can be clearly visible in case of GS and FS compared to VF and SF.

Linear regression analysis revealed a strong $\left(r^{2}=0.993\right)$ positive correlation between the applied cross-head speeds and the compressive strength values as shown in Figure 3 as well as the flexural strength values $\left(r^{2}=0.996\right)$ as presented in Figure 4 . Strength data of VD were taken as representatives for other studied materials.

For a group of investigated materials (GS, FS and VF) having, nearly, the same resin system (Bis-GMA, TEGDMA) and varied filler loading, linear regression analysis revealed a strong positive 
correlation between their compressive strength between their flexural strength and the filler loading values $(\mathrm{MPa})$ and the filler loading $\left(r^{2}=0.975\right)$, and $\quad\left(r^{2}=0.963\right)$ as shown in Figures 5 and 6 respectively.

TABLE (2) Mean data and standard deviations of compressive strength and flexural strength for the investigated resin-composites at three different cross-head speeds. Each strength value represents the mean of five measurements.

\begin{tabular}{|c|c|c|c|c|c|}
\hline Resin Composite & $\begin{array}{l}\text { Cross-head } \\
\text { Speed (mm/ } \\
\text { min) }\end{array}$ & $\begin{array}{c}\text { Mean Compressive } \\
\text { Strength (MPa) }\end{array}$ & $\begin{array}{c}\text { Standard } \\
\text { Deviation } \\
\text { (compressive) }\end{array}$ & $\begin{array}{l}\text { Mean Flexural } \\
\text { Strength (MPa) }\end{array}$ & $\begin{array}{l}\text { Standard } \\
\text { Deviation } \\
\text { (flexural) }\end{array}$ \\
\hline \multirow{3}{*}{ GrandioSo } & 1 & 427 & 15 & 175 & 6.1 \\
\hline & 3 & 429 & 21 & 178 & 7.5 \\
\hline & 5 & 434 & 18 & 182 & 5.8 \\
\hline \multirow{3}{*}{$\begin{array}{c}\text { Filtek Supreme } \\
\text { XTE }\end{array}$} & 1 & 413 & 22 & 161 & 6.9 \\
\hline & 3 & 417 & 19 & 164 & 7.5 \\
\hline & 5 & 421 & 16 & 168 & 6.7 \\
\hline \multirow{3}{*}{ Venus Diamond } & 1 & 392 & 25 & 137 & 6.3 \\
\hline & 3 & 398 & 23 & 142 & 8.1 \\
\hline & 5 & 406 & 28 & 146 & 7.2 \\
\hline \multirow{3}{*}{ Venus Flow } & 1 & 365 & 27 & 102 & 7.5 \\
\hline & 3 & 373 & 17 & 112 & 4.9 \\
\hline & 5 & 382 & 23 & 123 & 8.3 \\
\hline \multirow{3}{*}{$\begin{array}{c}\text { SureFil SDR } \\
\text { Flow }\end{array}$} & 1 & 349 & 19 & 84 & 6.9 \\
\hline & 3 & 358 & 21 & 96 & 8.7 \\
\hline & 5 & 367 & 24 & 105 & 7.9 \\
\hline
\end{tabular}

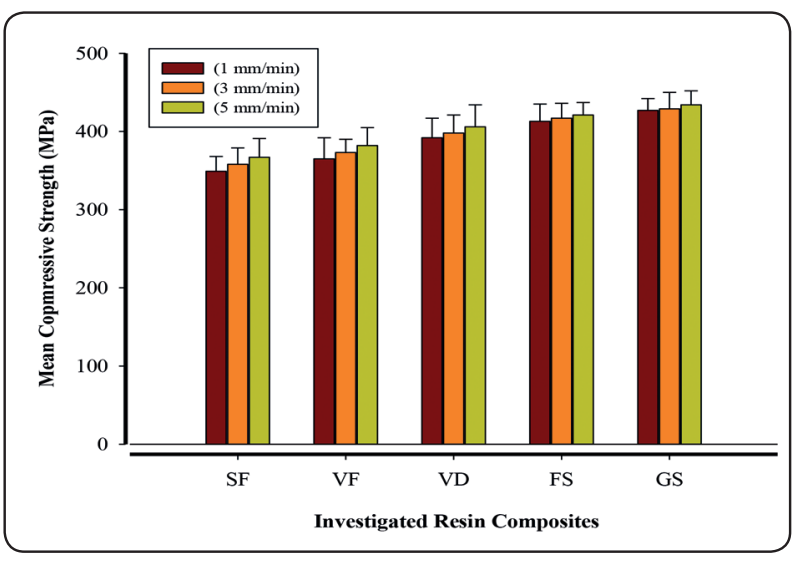

Fig. (1) Error bar showing mean compressive strength for the investigated resin-composites at three different crosshead speeds. Each bond strength value represents the mean of five measurements.

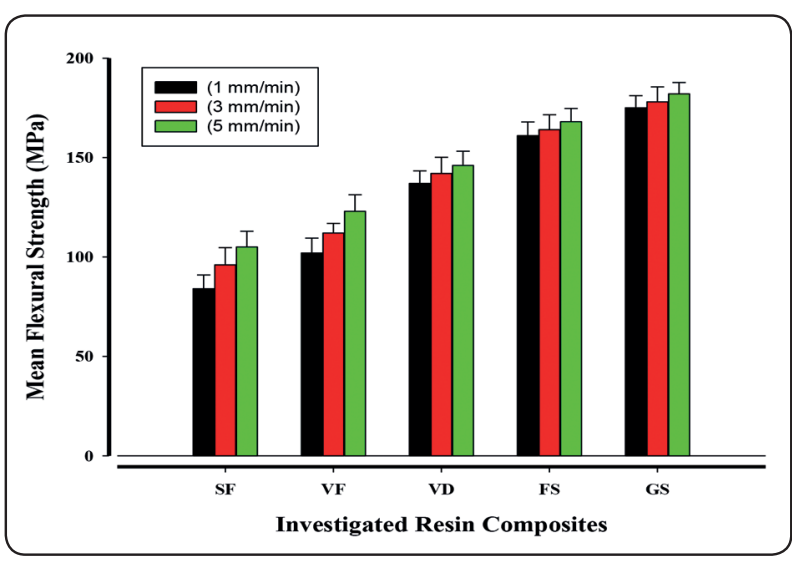

Fig. (2) Error bar showing mean flexural strength for the investigated resin-composites at three different crosshead speeds. Each bond strength value represents the mean of five measurements. 


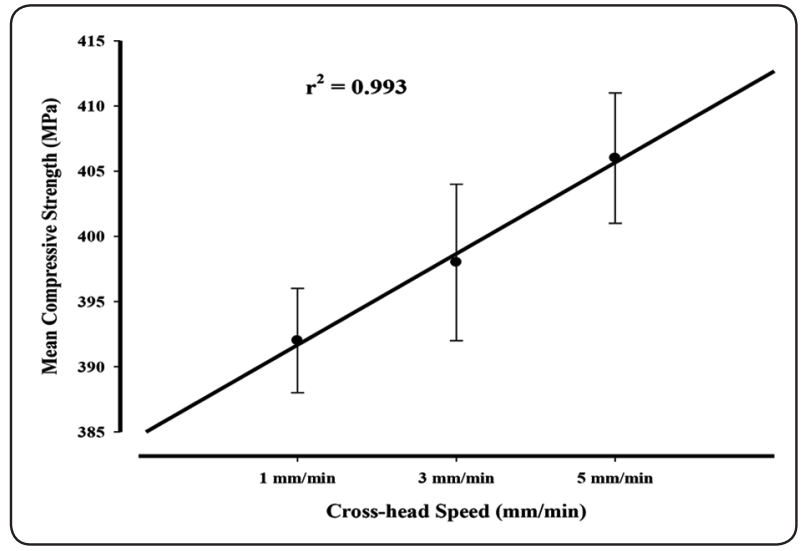

Fig. (3) Linear regression analysis for Venus Diamond (VD) - as a representative of the other materials - revealed a strong positive correlation between compressive strength values (MPa) and the applied cross-head speeds.

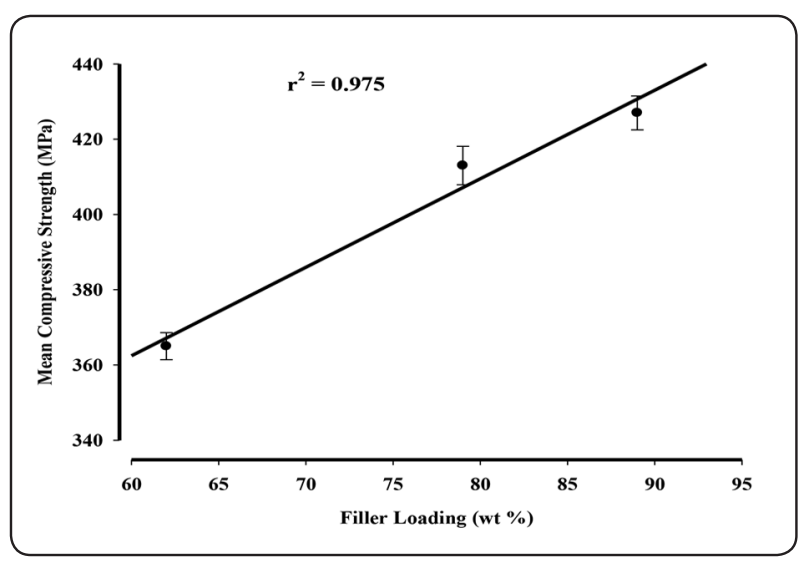

Fig. (5) For a group of investigated materials (GS, FS and VF) having the same resin system (Bis-GMA, TEGDMA) and varied filler loading, linear regression analysis revealed a strong positive correlation between their compressive strength values (MPa) and the filler loading.

\section{DISCUSSION}

Laboratory research and clinical trials are considered the main tools to characterize and evaluate the performance of resin-based restorative materials. An essential part of the critical evaluation of these materials is to examine their behavior under stress ${ }^{[23]}$.

Restoring both anterior and posterior teeth

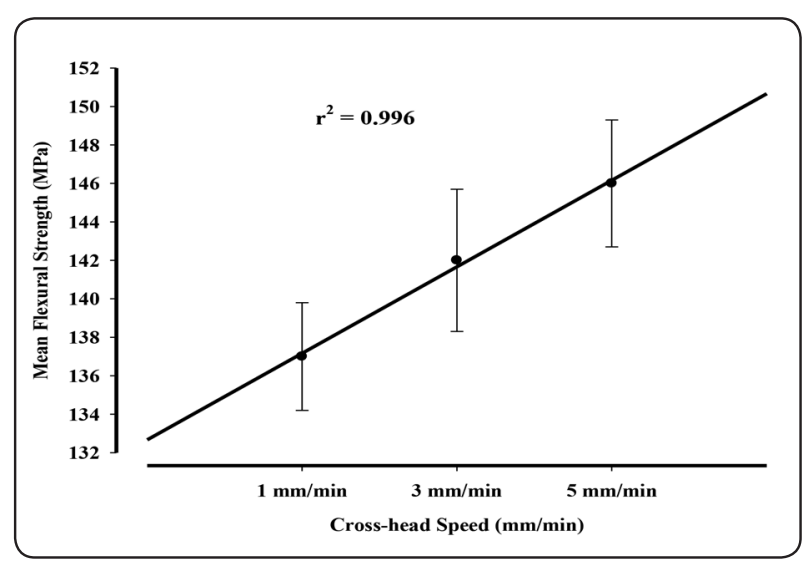

Fig. (4) Linear regression analysis for Venus Diamond (VD) - as a representative of the other materials - revealed a strong positive correlation between flexural strength values (MPa) and the applied cross-head speeds.

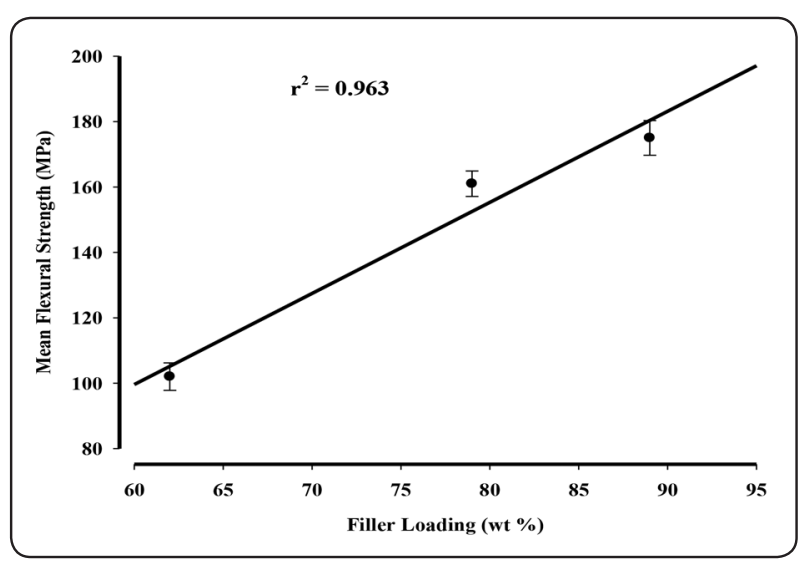

Fig. (6) For a group of investigated materials (GS, FS and VF) having the same resin system (Bis-GMA, TEGDMA) and varied filler loading, linear regression analysis revealed a strong positive correlation between their flexural strength values (MPa) and the filler loading.

with resin-composite materials is now an established clinical practice and the substitution of dental amalgam restorations by resin-composite restorations is increasing. The clinical performance and durability of these restorations are determined by many variables such as the filling technique, the patient's oral habits, the masticatory loading, and the physical and mechanical characteristics of the restorative material used ${ }^{[24,25]}$. 
It was reported that the loads in the local contact areas on the occlusal surface during chewing are about $66 \mathrm{~N}$, and under extremely high bite forces these loads can reach $90 \mathrm{~N}$ [26]. These relatively high forces indicate that high stresses fall on dental complex during function. Therefore, knowledge of the deformation behavior of resin-composite materials is important for predicting the functional behavior of such restorative materials in the mouth $^{[27]}$.

Resistance of dental restorative materials to degradation and distortion in the oral environment largely determines their durability and clinical performance ${ }^{[28]}$. Mechanical properties of resincomposites are influenced not only by their chemical composition, but also by the environment to which they are exposed ${ }^{[27]}$.

Special care was taken to ensure optimum curing of the materials during specimen preparation. This requires adequate irradiance of the curing unit, enough curing time, proper determination of the thickness of resin-composite material to be cured, and the contact between the curing tip and the specimen. It was said that incomplete polymerization may produce a heterogeneous specimen that has an uneven stress distribution during loading which, in turn, adversely affects the results of the mechanical properties measured ${ }^{[15,29]}$.

In this study, the compressive strength and flexural strength, as considered critical mechanical properties of any restorative material, were evaluated for some resin-composites of different nature and varied composition under three different crosshead speeds. This was carried out to investigate the behavior of such materials when loaded at different speeds. Statistical analysis revealed significant differences between the investigated materials at all cross-head speeds applied for both compressive strength and flexural strength, therefore, the first null hypothesis was rejected.

Also, varying the cross-head speed when loading these materials resulted in different strength values, i.e., when the cross-head speed was accelerated from $1 \mathrm{~mm} / \mathrm{min}$ to $3 \mathrm{~mm} / \mathrm{min}$ and then to $5 \mathrm{~mm} / \mathrm{min}$, the examined resin-composite materials showed greater mean values for both compressive strength and flexural strength. The second null hypothesis, consequently, was rejected as well.

Greater strength values with higher cross-head speeds may be interpreted on the basis that resincomposite materials are considered viscoelastic materials. The viscoelastic materials are "strain rate-sensitive" which means that at higher rate of loading, these materials exhibit higher strength and lower permanent deformation.

Linear regression analysis for all examined materials revealed a strong positive correlation between the cross-head speed applied and the resulting strength value for both compressive strength and flexural strength. Linear regression analyses of VD - as an example - were presented in Figure 3 ad Figure 4 for both compressive strength and flexural strength, respectively.

Addition of inorganic fillers has been repeatedly reported to improve the resistance of resin-based restorative materials against mechanical degradation ${ }^{[30]}$. The particular characteristics of filler particles, such as nature, distribution, content, and size in resincomposite materials determine to a great extent their strength and resistance to fracture ${ }^{[27,31]}$. The current study proved this information where materials with higher filler loading, such as GS and FS recorded greater values than those with lower filler loading, such as SF and VF both in compressive strength and flexural strength. In addition, for a group of investigated materials (GS, FS and VF) having the same resin system (Bis-GMA, TEGDMA) and varied filler loading, linear regression analysis revealed a strong positive correlation between their compressive strength values (MPa) and the filler loading as shown in Figure 5 and between their flexural strength and the filler loading as presented in Figure 6. 
Moreover, deformation or fracture of resincomposite materials is greatly dependent on the monomer type and diluent concentration in the matrix formulation. For a given filler loading, resincomposites with rigid monomers, such as Bis-GMA, and low concentration of diluent, such as TEGDMA, exhibit greater strength values than do other resincomposites with other monomer type and higher diluent concentration ${ }^{[32,33]}$. In this study, though SF has higher filler loading (68 wt $\%$ ) than VF (62 $\mathrm{wt} \%$ ), the latter (VF) exhibited greater mean values in both compressive strength and flexural strength than the former (SF). This could be explained on the basis that VF has Bis-GMA in its resin formulation while SF is based on other monomer system.

Though compressive strength and flexural strength are important mechanical properties, selecting a material for restoring teeth, particularly in the posterior region, does not depend on these two properties alone. Instead, there are many other physical and mechanical properties that must be considered such as elastic modulus, hardness, resistance to wear, polymerization shrinkage, environmental degradation and esthetics ${ }^{[34]}$.

\section{CONCLUSIONS}

- Resin-composites with different composition exhibited varied values of both compressive strength and flexural strength.

- Variation in cross-head speed resulted in variation in strength values of the investigated materials.

- The values of compressive strength and flexural strength depend principally on the extent of filler loading and the resin system.

\section{REFERENCES}

1. Musanje L, Darvell BW. Effects of Strain Rate and Temperature on the Mechanical Properties of Resin Composites. Dental Materials, 2004; 20:750-765.

2. Manhart J, Kunzelmann KH, Chen HY, Hickel R. Mechanical Properties of New Composite Restorative Materials. Journal of Biomedical Materials Research, 2000; 53:353-361.
3. Vaidyanathan J, Vaidyanathan TK. Flexural Creep Deformation and Recovery in Dental Composites. Journal of Dentistry, 2001; 29:545-551.

4. He LH, Swain MV. Nanoindentation Derived Stress-Strain Properties of Dental Materials. Dental Materials, 2007; 23:814-821.

5. Pilo R, Brosh T, Lugassy H, Baharav H, Helft M. The Effect of Irradiation Time on the Shear Strength of Composites. Dental Materials, 1994; 10:338-342.

6. Manhart J, Kunzelmann KH, Chen HY, Hickel R. Mechanical Properties and Wear Behavior of Light-Cured Packable Composite Resins. Dental Materials, 2000; 16:33-40.

7. Kawaguchi M, Fukushima T, Horibe T. Effect of Monomer Structure on the Mechanical Properties of Light-Cured Composite Resins. Dental Materials Journal,1989;8:40-45.

8. Söderholm KJ, Zigan M, Ragan M, Fischlschweiger W, Bergman M. Hydrolytic Degradation of Dental Composites. Journal of Dental Research, 1984; 63:1248-1254.

9. Sarkar NK. Internal Corrosion in Dental Composite Wear: its Significance and Simulation. Journal of Biomedical Materials Research, 2000; 53:371-380.

10. Irie M, Tjandrawinata REL, Yamashiro T, Kazuomi S. Flexural Performance of Flowable Versus Conventional Light-Cured Composite Resins in a Long-Term in Vitro Study. Dental Materials Journal, 2008; 27:300-309.

11. Ho CT, Vijayaraghavan TV, Lee SY, Tsai A, Huang HM, Pan LC. Flexural Behaviour of Post-Cured Composites at Oral-Simulating Temperatures. Journal of Oral Rehabilitation, 2001; 28:658-667.

12. Brosh T, Ganor Y, Belov I, Pilo R. Analysis of Strength Properties of Light-Cured Resin Composites. Dental Materials, 1999; 15:174-179.

13. Chung KH. The Relationship between Composition and Properties of Posterior Resin Composites. Journal of Dental Research, 1990; 69:852-856.

14. Baharav H, Brosh T, Pilo R, Cardash H. Effect of Irradiation Time on Tensile Properties of Stiffness and Strength of Composites. Journal of Prosthetic Dentistry, 1997; 77:471-474.

15. Nayif MM, Nakajima M, Foxton RM, Tagami J. Effect of Light Irradiation Time on the Mechanical Properties of Two Flowable Composites with Different Initiation Systems in Bonded and Unbonded Cavities. Dental Materials Journal, 2007; 26:687-693. 
16. Silva CM, Dias KRHC. Compressive Strength of Esthetic Restorative Materials Polymerized with Quartz-TungstenHalogen Light and Blue LED. Brazilian Dental Journal, 2009; 20:54-57.

17. Sunnegårdh-Grönberg K, Peutzfeldt A, Van Dijken JWV. Flexural Strength and Modulus of a Novel Ceramic Restorative Cement Intended for Posterior Restorations as determined by a Three-Point Bending Test. Acta Odontologica Scandinavica, 2003; 61:87-92.

18. Lambrechts P, Braem M, Vanherle G. Evaluation of Clinical Performance of Posterior Composite Resins and Dentin Adhesives. Operative Dentistry, 1987; 12:53-78.

19. Miyazaki M, Oshida Y, Moore BK, Onose H. Effect of Light Exposure on Fracture Toughness and Flexural Strength of Light-Cured Composites. Dental Materials, 1996; 12:328-332.

20. Williams JA, Billington RW. Increase in Compressive Strength of Glass Ionomer Restorative Materials with Respect to Time: A Guide to Their Suitability for Use in Posterior Primary Dentition. Journal of Oral Rehabilitation, 1989; 16:475-479.

21. Moniruzzaman M, Du F, Romero N, Winey KI. Increased Flexural Modulus and Strength in SWNT/Epoxy Composites by a New Fabrication Method. Journal of Polymer Science, 2006; 47:293-298.

22. Kakuta K, Urapepon S, Miyagawa Y, Ogura H, Yamanaka M, Suchatlampong C, Rittapai A. Development of MetalResin Composite Restorative Material: Part 4. Flexural Strength and Flexural Modulus of Metal-Resin Composite Using Ag-In Alloy Particles as Filler. Dental Materials Journal, 2002; 21:181-190.

23. Tanimoto Y, Hirayama S, Yamaguchi M, Nishiwaki T. Static and Dynamic Moduli of Posterior Dental Resin Composites under Compressive Loading. Journal of the Mechanical Behavior of Biomedical Materials, 2011; 4:1531-1539.
24. von Fraunhofer JA, Curtis Jr P. The Physical and Mechanical Properties of Anterior and Posterior Composite Restorative Materials. Dental Materials, 1989; 5:365-368.

25. Burke FJT, Lucarotti PSK, Holder RL. Outcome of Direct Restorations Placed within the General Dental Services in England and Wales (Part 2): Variation by Patients' Characteristics. Journal of Dentistry, 2005; 33:817-826.

26. Laurell L, Lundgren D. A Standardized Programme for Studying the Occlusal Force Pattern During Chewing and Biting in Prosthetically Restored Dentitions. Journal of Oral Rehabilitation, 1984; 11:39-44.

27. Oden A, Ruyter IE, Oysaed H. Creep and Recovery of Composites for Use in Posterior Teeth During Static and Dynamic Compression. Dental Materials, 1988; 4:147-150.

28. Roulet JF, Walti C. Influence of Oral Fluid on Composite Resin and Glass-Ionomer Cement. The Journal of Prosthetic Dentistry, 1984; 52:182-189.

29. Masouras K, Silikas N, Watts DC. Correlation of Filler Content and Elastic Properties of Resin-Composites. Dental Materials, 2008; 24:932-939.

30. Papadogiannis Y, Lakes RS, Petrou-Americanos A, Theothoridou-Pahini S. Temperature Dependence of the Dynamic Viscoelastic Behavior of Chemical- and LightCured Composites. Dental Materials, 1993; 9:118-122.

31. Ruyter IE, Oysaed H. Compressive Creep of Light Cured Resin Based Restorative Materials. Acta Odontologica Scandinavica, 1982; 40:319-324.

32. Ferracane JL, Matsumoto H, Okabe T. Time-Dependent Deformation of Composite Resins--Compositional Considerations. Journal of Dental Research, 1985; 64:1332-1336.

33. Bayne SC, Thompson JY, Swift EJ, Stamatiades P, Wilkerson M. A Characterization of First-Generation Flowable Composites. Journal of American Dental Association, 1998; 129:567-577.

34. Nakayama WT, Hall DR, Grenoble DE, Katz JL. Elastic Properties of Dental Resin Restorative Materials. Journal of Dental Research, 1974; 53:1121-1126. 